\title{
Correlation of supercritical-fluid extraction recoveries with supercritical-fluid chromatographic retention data: A fundamental study
}

\section{Citation for published version (APA):}

Lou, X. W., Janssen, J. G. M., \& Cramers, C. A. M. G. (1995). Correlation of supercritical-fluid extraction recoveries with supercritical-fluid chromatographic retention data: A fundamental study. Journal of High Resolution Chromatography, 18(8), 483-489. https://doi.org/10.1002/jhrc.1240180805

DOI:

10.1002/jhrc.1240180805

Document status and date:

Published: 01/01/1995

\section{Document Version:}

Publisher's PDF, also known as Version of Record (includes final page, issue and volume numbers)

\section{Please check the document version of this publication:}

- A submitted manuscript is the version of the article upon submission and before peer-review. There can be important differences between the submitted version and the official published version of record. People interested in the research are advised to contact the author for the final version of the publication, or visit the $\mathrm{DOI}$ to the publisher's website.

- The final author version and the galley proof are versions of the publication after peer review.

- The final published version features the final layout of the paper including the volume, issue and page numbers.

Link to publication

\footnotetext{
General rights

- You may freely distribute the URL identifying the publication in the public portal. follow below link for the End User Agreement:

www.tue.nl/taverne

\section{Take down policy}

If you believe that this document breaches copyright please contact us at:

openaccess@tue.nl

providing details and we will investigate your claim.
}

Copyright and moral rights for the publications made accessible in the public portal are retained by the authors and/or other copyright owners and it is a condition of accessing publications that users recognise and abide by the legal requirements associated with these rights.

- Users may download and print one copy of any publication from the public portal for the purpose of private study or research.

- You may not further distribute the material or use it for any profit-making activity or commercial gain

If the publication is distributed under the terms of Article $25 \mathrm{fa}$ of the Dutch Copyright Act, indicated by the "Taverne" license above, please 


\section{Correlation of Supercritical-Fluid Extraction Recoveries with Supercritical-Fluid Chromatographic Retention Data: A Fundamental Study}

Xianwen Lou, Hans-Gerd Janssen*, and Carel A. Cramers

Eindhoven University of Technology, Laboratory of Instrumental Analysis, P.O. Box 513, 5600 MB Eindhoven, The Netherlands

\section{Key Words:}

Supercritical-Fluid Extraction (SFE)

Supercritical-Fluid Chromatography (SFC)

Recovery

Optimization

Retention Data

\section{Summary}

The possibility of using supercritical-fluid chromatographic retention data for examining the effects of operational parameters, such as pressure and flow rate, on the extraction characteristics in supercritical-fluid extraction (SFE) was investigated. A model was derived for calculating the extraction efficiency in SFE from retention data and peak shapes measured in supercritical-fluid chromatography (SFC). By performing the SFC experiments at the same pressure and temperature as the SFE extractions using the SFE extraction cell as the SFC column, an accurate prediction of extraction efficiencies could be made. Finally, the effects of matrix composition and analyte concentration on extraction efficiency were studied.

\section{Introduction}

Supercritical fluid extraction (SFE) is a relatively new and rapidly growing technique for sample preparation in analytical chemistry [1]. SFE has been recognized as an important alternative to conventional liquid or Soxhlet extraction and provides many advantages, such as a reduced use of organic solvents, shorter extraction time, adjustable solvent strength, and the capability of on-line transfer of the extracted components to other analytical instruments [2-5].

In trace analysis, the ability to rapidly remove the extraction fluid simply by pressure release and venting is a significant advantage of SFE over liquid extraction. In conventional extraction techniques, the extracts often have to be reconcentrated prior to introduction into the analytical separation system. SFE extracts can be collected in a very small volume of liquid or even in dry collection tubes. For this reason, SFE is particularly promising for trace analysis. Unfortunately, however, SFE also has a number of disadvantages. Among these is the price of the instrumentation and, more importantly, the time consuming nature of method development. Many parameters affect the SFE process, e.g. temperature, pressure, modifier type, and concentration as well as solute parameters such as molecular weight, polarity, and volatility, and matrix properties such as particle size, pore structure, and adsorptive strength. The numerous parameters that influence the extraction process and the lack of fundamental knowledge about how these parameters affect the extraction are to blame for the fact that method development in SFE up till now has remained mainly empirical. Current optimization strategies for SFE are almost exclusively based on trial and error experiments.
The SFE process basically involves three consecutive steps. First, the solutes have to diffuse from the core of the matrix-particles to the surface. Obviously, this step is absent if the components are adsorbed on the surface of a particle, which is for example the case for components that are extracted from an SPE cartridge or from sandy soil. Next, the components are transferred from the particle surface into the extraction fluid. The key parameter that controls this process is the distribution coefficient of the solute between the matrix and the supercritical fluid phase. Finally, the components are eluted from the extraction cell by the flow of supercritical extractant. The last two steps of the extraction process are somewhat similar to the process occurring in supercritical fluid chromatography (SFC). Hence, the extraction behavior for samples in which these two steps determine the rate of extraction should be at least qualitatively related to the retention behavior of the solutes in SFC.

Optimization of SFE has been the subject of numerous papers in the recent chromatographic literature [6-16]. Most of these articles rely on empirical optimization. A limited number of more fundamental studies was published in which attempts were made to increase fundamental knowledge of the thermodynamic and kinetic parameters that impact on SFE. Bartle et al. [6] derived a model that allowed the calculation of the extraction kinetics in an SFE system where the rate-governing step is slow mass transfer inside the matrix particles. King [7] published a mathematical model that permits the calculation of the solubility of organic compounds in supercritical fluids from molecular parameters. McNally and Wheeler $[8,9]$ attempted to correlate SFC retention data of diuron and linuron measured on an octadecyl material with the extraction behavior of these components from soil in SFE. Similar work was done by Furton et al. [10].

Bartle's model yielded an excellent agreement between theory and practical results in the case where the first step in the extraction process, i.e. diffusion in the solid particle, is the rate-limiting parameter. A typical SFE application where this situation occurs is the extraction of polymer additives from polymeric particles. In other important application areas of SFE, the components are adsorbed on the surface of a particle such as a sandy soil or an SPE sorbent. In these cases, no diffusion of the components from the core of the particle to the surface has to occur. Therefore, the key parameter controlling the extraction behavior for these samples is the distribution coefficient of the solute between matrix and supercritical fluid. The distribution coefficient is the result of competition between the supercritical fluid extractant and the 
matrix for the solute. In analytical SFE, the analyte concentration in the matrix is generally low. Hence, the solubility of the components in the extraction fluid is generally not a limiting parameter. The observation that small variations in sample matrix composition can require substantial adjustment of the extraction parameters appears to indicate that effects associated with the matrix are far more important [16].

In chromatography, the capacity factor, being the quotient of the distribution coefficient and the phase ratio, represents the ratio of the amount of the component retained in the stationary phase to the amount present in the mobile phase. Therefore, the extraction kinetics in SFE should at least be qualitatively related to the capacity factors of the components measured in SFC using the matrix that is to be extracted as the stationary phase. In more general terms, the knowledge of extraction kinetics in SFE can be improved by studying the retention behavior in packed column SFC.

In the packed-column SFC separation of polar components asymmetrical peaks are very often observed. The cause of the poor peak shape is the presence of residual active sites on the packing material $[17,18]$. These active sites tend to interact strongly with the analytes thereby resulting in non-linear isotherms. Moreover, for such systems, the distribution coefficient becomes concentration dependent. If now a similar situation occurs in SFE, this would mean that the extraction yields obtained in a given extraction time under given experimental conditions could also be affected by the concentration of the analytes in the matrix. Schoenmakers et al. $[17,18]$ studied the distribution isotherms of polar components on inhomogeneous stationary phases in SFC and found that the retention decreased with increasing sample size. Up till now, the effects of concentration on the extraction efficiency in SFE have not been investigated yet.

The aim of the present work is to investigate whether retention data of the components of interest measured on the sample matrix using SFC can provide a means of gaining knowledge of the extraction kinetics in SFE. After extraction, the components of interest are injected by means of an SFC injection valve incorporated in the SFE set-up and the retention data and peak shapes are determined. SFE elution profiles are then correlated with retention data and peak shapes of the components as obtained in the SFC mode. A model is derived that allows the calculation of extraction yields from retention data and peak shapes measured under SFC conditions using the extraction cell as the chromatographic column. The predicted recoveries are compared with experimentally observed extraction yields. Furthermore, the effects of analyte concentration on the kinetics of extraction were investigated.

\section{Theory}

Supercritical fluid chromatography and supercritical fluid extraction have in common the use of a supercritical fluid for eluting the analytes. In both techniques, there is a stagnant phase that tends to retain the probe molecules. The matrix in SFE can be looked upon as a kind of stationary phase that retains the analytes analogous to a true stationary phase in SFC. In this section a model will be derived that allows the calculation of extraction yields in SFE from retention data and peak shapes measured in the SFC mode using the extraction cell as the chromatographic column.

For components adsorbed on the surface of the matrix, equilibration is fast. The distribution of the analytes between the matrix and the supercritical fluid after equilibration can be expressed by the distribution coefficient. The distribution coefficient, $K$, is defined as the ratio of concentrations in the two phases:

$K=\frac{c_{\mathrm{ma}}}{c_{\mathrm{sf}}}=\frac{m_{\mathrm{ma}} V_{\mathrm{sf}}}{m_{\mathrm{sf}} V_{\mathrm{ma}}}=\frac{\beta m_{\mathrm{ma}}}{m_{\mathrm{sf}}}$

where $c$ and $m$ are the concentration and weight of the components in the two phases, respectively. $\mathrm{V}$ is the volume of the matrix and the supercritical fluid, and $\beta$ is the phase ratio. The subscripts "ma" and "sf" refer to "matrix" and "supercritical fluid", respectively.

For a given compound under given experimental conditions, $K$ is the thermodynamic distribution coefficient which can be measured by SFC. If now the SFE and SFC experiments are carried out on the same packing under identical experimental conditions, the distribution coefficient obtained in SFC is also valid for SFE. Hence,

$K_{\mathrm{sfe}}=K_{\mathrm{sfc}}=\beta_{\mathrm{sfc}} k_{\mathrm{sfc}}^{\prime}$

Combining eqs. (1) and (2) yields

$\frac{m_{\text {sf }}}{m_{\mathrm{ma}}}=\frac{\beta_{\text {sfe }}}{\beta_{\text {sfc }} k_{\text {sfc }}^{\prime}}$

Where $m_{\mathrm{sf}}$ and $m_{\mathrm{ma}}$ are the amounts of the test compound dissolved in the supercritical fluid and adsorbed on the matrix, respectively.

The fraction of solute present in the supercritical fluid, $R$, is given by:

$R=\frac{m_{\mathrm{sf}}}{m_{\mathrm{sf}}+m_{\mathrm{ma}}}$

Here $R$ actually represents the extraction yield obtained in a static extraction. Combining eqs. (3) and (4) yields

$R=\frac{\beta_{\mathrm{sfe}}}{\beta_{\mathrm{sfe}}+\beta_{\mathrm{sfc}} k_{\mathrm{sfc}}^{\prime}}$

We can now define a parameter $\alpha$ which represents the ratio of the phase ratios under SFE and SFC conditions:

$\alpha=\frac{\beta_{\text {sfc }}}{\beta_{\text {sfe }}}$

In the present work all SFE and SFC experiments were carried out using the cartridge packed with the sample both as the extraction cell and as the SFC column. Hence, the value of $\alpha$ was unity throughout this work. This means that eq. (5) can be simplified to:

$R=\frac{1}{1+k_{\mathrm{sfc}}^{\prime}}$

where $k_{\text {sfc }}^{\prime}$ is the capacity factor of the analyte as determined by SFC. 


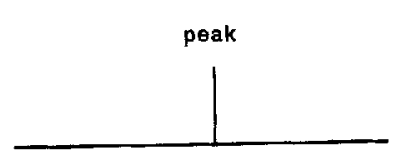

A

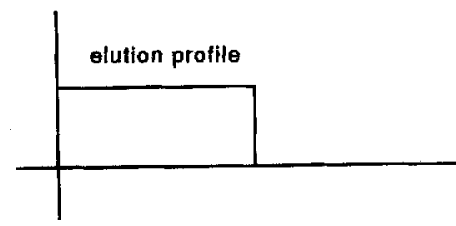

B

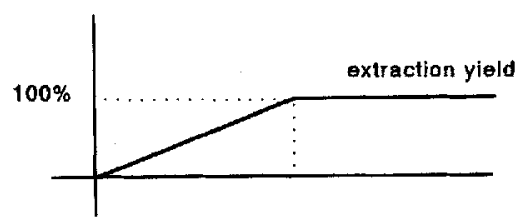

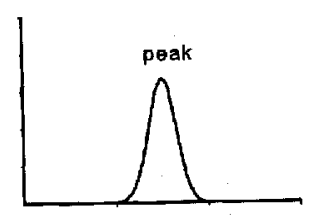

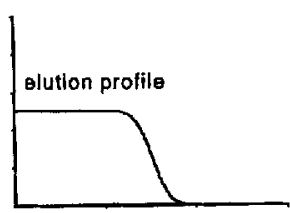

$E$

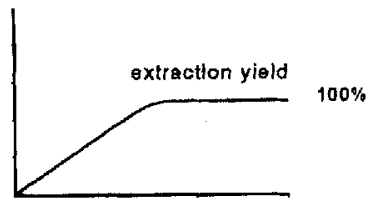

Figure 1. Relationship between peak shape, calculated SFE elution profile and extraction yield $v$ s time curve. 1A - 1C: hypothetical extraction cell with an infinite plate number; $1 \mathrm{D}-1 \mathrm{~F}$ : extraction cell with a finite plate number.

In order to calculate the extraction yields, the SFE elution profile was studied. For systems in which the extraction rate is determined by transfer of the solute from the particle surface into the fluid, it can be assumed that equilibrium between the supercritical fluid and the matrix is established in a short period of static extraction. Moreover, for these systems there is no concentration gradient along the cell. In the hypothetical case that we have an extraction cell with an infinite plate number, the time required to elute the components is identical to the time required to elute the sample molecules that were originally present at the very top of the extraction cell. This time equals the retention time in SFC. Under the conditions specified above, the analytes elute at a constant rate and extraction is complete at the analyte retention time. Plots of the extraction rate vs. time curve and of the corresponding SFC chromatogram for this hypothetical system are given in Figure 1A - 1C.

In SFE systems with a finite plate number, the time required to quantitatively extract the components is increased due to bandspreading. As the degree of band-spreading in SFE of the components originally present at the very top of the extraction cell is identical to that in SFC, the time required to obtain quantitative extraction in SFE equals the time required to obtain complete elution in SFC. Due to the band-spreading, a gradual decrease in extraction rate occurs towards the end of the extraction resulting in a smooth transition in the extraction yield vs. time curve.

In mathematical terms, the extraction yield vs. time curves as given in Figure 1C, can be obtained by integration of the extraction rate vs. time curves given in Figure 1B. The shape of the extraction rate vs. time curve for an SFE cell with an infinite plate number is easy to predict (Figure 1B). The prediction of extraction rate vs. time curves for cells with a finite plate number requires the use of a mathematical technique called convolution. Basically, convolution of two functions equals multiplication of these functions. Convolution of the extraction rate curve obtained for a system with an infinite plate number with a transfer function that represents the response of a more realistic system with a finite plate number to a very narrow input signal gives the $e x$ traction rate $v$ s. time curve for an SFE cell with a finite plate number. The response of the system to a narrow input signal is simply the chromatographic peak.

In static SFE after equilibrium between the supercritical fluid and the matrix has been established, the analytes elute at a constant rate from the beginning of the dynamic extraction. Using convolution techniques, the elution profile in SFE can be expressed as:

$r(t)=\frac{M}{t_{0}\left(1+k^{\prime}\right)} \times\left[1-\frac{\int_{0}^{t} c(t) \mathrm{d} t}{\int_{0}^{\infty} c(t) \mathrm{d} t}\right]$

where $r(t)$ is the extraction rate at time $t, M$ is the total amount of the analyte, $t_{0}$ is the time needed to elute the void volume of the cell, and $c(t)$ is the SFC elution profile.

The extraction yield, $Y$, can be calculated from:

$Y=\frac{\int_{0}^{t} r(t) \mathrm{d} t}{M}$

If the elution profile in SFC, $c(t)$, can be represented by a Gaussian peak, eq. (8) can be rewritten as:

$r(t)=\frac{M}{t_{0}\left(1+k^{\prime}\right)} \times\left(1-\int_{0}^{t} \frac{1}{\sqrt{2 \pi} \sigma} \mathrm{e}^{-\left(\mathrm{t}-\mathrm{t}_{\mathrm{r}}\right)^{2} / 2 \sigma^{2}} \mathrm{~d} t\right)$ 
where $t_{\mathrm{r}}$ is the retention time of the component, and $\sigma$ the standard deviation.

Combining eqs. (9) and (10) yields:

$Y=\frac{\int_{0}^{t}\left(1-\int_{0}^{t} \frac{1}{\sqrt{2 \pi} \sigma} \mathrm{e}^{-\left(\mathrm{t}-\mathrm{t}_{1}\right)^{2} / 2 \sigma^{2}} \mathrm{~d} t\right) \mathrm{d} t}{t_{0}\left(1+k^{\prime}\right)}$

The extraction rate and extraction yield $v$ s. time curves calculated from an SFC peak for an SFE cell with a finite plate number are shown in Figure 1D - 1F.

Up till now, it has been assumed that the capacity factors of the components are independent of the solute concentration and that the sample matrix to be extracted is well defined and homogeneous (e.g. the extraction of non-polar components from an SPE adsorbent). For inhomogeneous samples where the sample matrix contains active sites for the solutes, however, various interaction mechanisms between the analyte and the matrix might contribute independently to the overall retention of the analytes, e.g. interaction with organic material and with active sites present in the matrix. In this case, a mixed retention mechanism [17] must be used, where

$k_{\text {tot }}^{\prime}(c)=k_{\text {part }}^{\prime}+k_{\text {ads }}^{\prime}(c)$

Here $k_{\text {tot }}^{\prime}(c)$ is the overall capacity factor, $k_{\text {part }}^{\prime}$ and $k_{\text {ads }}^{\prime}(c)$ are the capacity factors due to partitioning and adsorption, respectively. The addition of $(c)$ indicates the dependence of the parameter on the concentration of the analytes. For SFC systems in which such a situation occurs, lower capacity factors are often observed at higher concentration levels. In the case that the capacity factor is concentration dependent, eqs. (8) - (11) are no longer valid. It is one of the aims of the present work to investigate whether the analyte concentration affects the extraction characteristics of SFE.

\section{Experimental}

The experimental work was carried out on a modified Carlo Erba SFC 3000 capillary SFC instrument (Carlo Erba, Milan, Italy). A stainless steel HPLC column $(0.5 \mathrm{~cm}$ i.d. $\times 10 \mathrm{~cm}$ length) obtained from Knauer (Berlin, Germany) was used as the extraction cell. Fused-silica capillaries $(20 \mu \mathrm{m}$ i.d., with different lengths) were used as restrictors. To enable static extractions an on-off valve (Valco, Switzerland) was installed directly behind the extraction cell. The supercritical fluid flow from the extraction cell was split into two streams in a low dead-volume T-piece (Gerstel GmbH, Mülheim a/d Ruhr, Germany). One stream (approximately $2 \%$ ) was fed to the flame ionization detector (FID) for detection, while the other was directed towards the sample collection device. A schematic representation of the instrument is given in Figure 2.

All experiments were performed at $50^{\circ} \mathrm{C}$ unless stated otherwise. The analytes were extracted at 200 bar (from sand) or 300 bar (from ODS) after a 5 minute static period at the same pressure. The carbon dioxide used in the experiments had a purity of 99.996\% (Intermar B.V. Breda, The Netherlands). An octadecylsilane solid phase material (ODS, $40 \mu \mathrm{m}$ particle size, J.T. Baker Inc., Philipsburg, NJ USA) and sand were selected as model matrices. The test solutes were octadecane, eicosane, cyclohex-

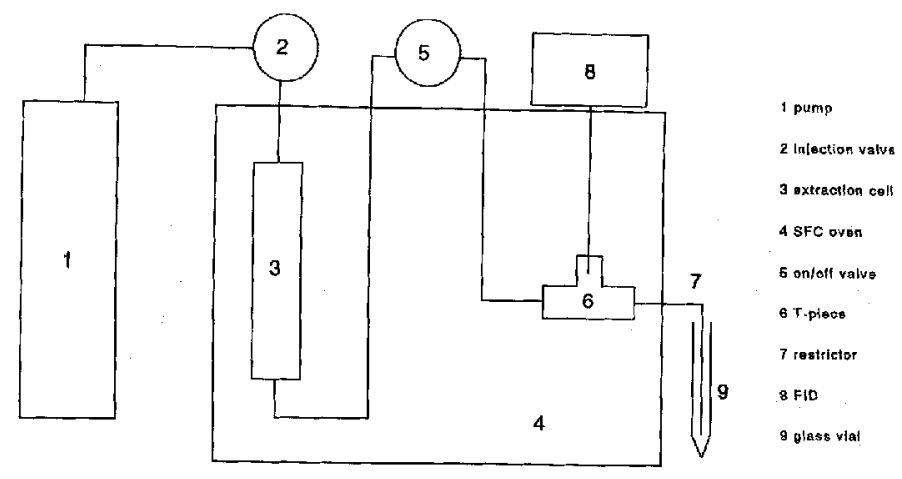

Figure 2. Schematic diagram of the experimental set-up.

anone, and hexadecanol (all obtained from Fluka AG., Buchs SG, Switzerland). The extracted material was collected by inserting the restrictor outlet into a glass vial $(10 \mathrm{~cm} \times 1 \mathrm{~cm}$ i.d. $)$ containing an internal standard and $5 \mathrm{ml}$ organic solvent. Hexane was selected as the collection solvent for octadecane and eicosane while dichloromethane was used for the collection of hexadecanol.

After collection, the solution was concentrated under a gentle flow of nitrogen and analyzed using a gas chromatograph equipped with an on-column injector and an FID (GC 8000 series, Carlo Erba Instruments). The gas chromatographic separation was achieved on a crosslinked PEG-20 M capillary column $(25 \mathrm{~m} \times 0.32 \mathrm{~mm}$ i.d., film thickness $1.2 \mu \mathrm{m})$ purchased from Chrompack (Middelburg, The Netherlands).

\section{Results and Discussion}

Although very different at first sight, SFE and packed column SFC are very much similar in many respects. In both techniques, a supercritical fluid is used for dissolving the components and transporting the analytes through a packed bed of solid particles, i.e. the stationary phase in SFC or the matrix in SFE. If an analyte exhibits a strong interaction with the matrix, this will result in a high capacity factor in SFC and a poor extractability in SFE. Similarly, a packed cell exhibiting large band spreading in SFC is unlikely to yield sharp extraction curves in SFE. From this it is plausible to assume that retention and peak shapes observed in SFC on the one hand and the extraction profile in SFE on the other hand are correlated.

In the theory section, equations have been derived that allow the calculation of SFE extraction rates and yields from chromatographic retention data and peak shapes (eqs. (7), (8), and (10)). From these equations, the following conclusions can be drawn:

(a) the fraction of solute present in the supercritical fluid will decease with increasing $k_{\mathrm{sfc}}$;

(b) if static extraction is followed by solventless collection of the analytes in a rapid depressurization step without subsequent dynamic extraction [19], quantitative recovery can only be obtained if $k^{\prime}$ is zero;

(c) any parameter affecting $k$ in SFC will affect the SFE extraction kinetics.

(d) the extraction rate will decrease with increasing $k^{\prime}$ and/or to. 
These conclusions are in agreement with observations that better recoveries for $\mathrm{SFE}$ can be achieved by working under conditions that lead to reduced capacity factors in SFC, such as increased supercritical fluid density or the addition of modifiers [10].

The extraction rate vs. time curve calculated from eq. (8) shows that after an initial period in which elution occurs at a constant rate, the extraction rate starts to decrease and finally reaches zero at the time when extraction is complete. The width of the constant elution rate range is determined by both the solute retention time and the column efficiency of the extraction cell. That is, the time needed for complete extraction is controlled by both the solute retention time and the extraction cell efficiency. For a Gaussian peak, the SFE extraction yield at the point of the retention time of the solute in SFC can be calculated by eq. (11). The results can be approximated by:

$Y \approx 1-\frac{1}{2 \sqrt{N}}$

where $N$ is the plate number of the extraction cell.

From this equation, it can be seen that the column efficiency of the extraction cell has a considerable effect on the SFE extraction behavior. If the plate number of the extraction cell would be infinite, the extraction would be complete at the solute retention time. For a more realistic extraction cell with a finite plate number, the extraction yield at the solute retention time is less than $100 \%$

In order to correlate the SFE extraction kinetics with SFC retention data and peak shapes, SFC experiments were carried out immediately after the SFE experiments using the SFE cell as the SFC column. In Figure 3 overlays are shown of the SFE elution profiles and the SFC chromatograms of octadecane at $50^{\circ} \mathrm{C}$ and different pressures. The elution profiles calculated directly from the chromatographic peak shapes using the convolution technique are also shown in this figure. A number of interesting conclusions can be drawn from these plots. First, it can be seen that a very good agreement between the experimental extraction profile and the calculated profile is obtained. As predicted, the analytes elute at a constant rate from the start of the dynamic extraction until close to the retention time of the component in the SFC experiment. Then, the extraction rate starts to decrease at the point where elution of the component begins. As is evident from the figure, complete recovery of a component in SFE is achieved after the time when the component is fully eluted from the extraction cell in the SFC experiment. These observations prove that the extraction behavior in SFE is indeed closely related to retention in SFC.

In the preceding paragraph, good agreement was observed between the experiments and the predicted trends in the extraction of non-polar components from ODS. However, for inhomogeneous systems, where a mixed-retention mechanism can occur, the capacity factors of the components become concentration dependent and the eqs. (8) - (11) are no longer valid. In this case, it is no longer possible to calculate the SFE elution profiles directly from SFC retention data and peak shapes as is evident from Figure 4. This figure shows the SFE elution rate vs. time curve for the extraction of cyclohexanone from ODS at $40{ }^{\circ} \mathrm{C}$ and 300 bar together with the SFC chromatograms of the component for different sample sizes obtained under identical experi-
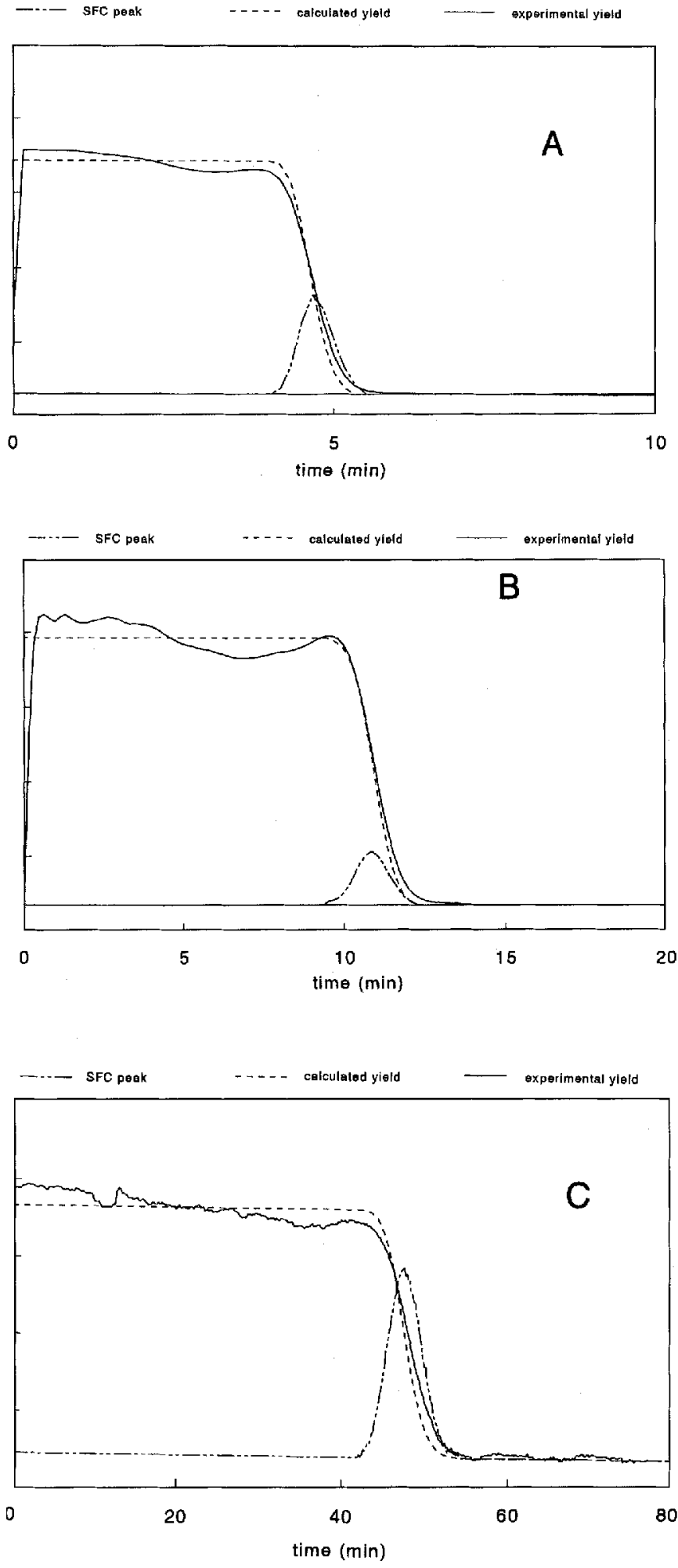

Figure 3. Comparison of experimental SFE elution profiles of octadecane from ODS with profiles calculated from SFC peaks. Experimental conditions: $50^{\circ} \mathrm{C}$; SFE extractions were performed by dynamic extraction after a 5 minutes static period at different pressures. 3A: 300 bar; 3B: 200 bar; 3C: 120 bar.

mental conditions. The SFC peaks are broad and tailing due to the interaction of the solute with active sites present on the ODS material [20]. The SFE elution profile shows that the solute elutes at a constant rate from the start of the dynamic extraction until a 


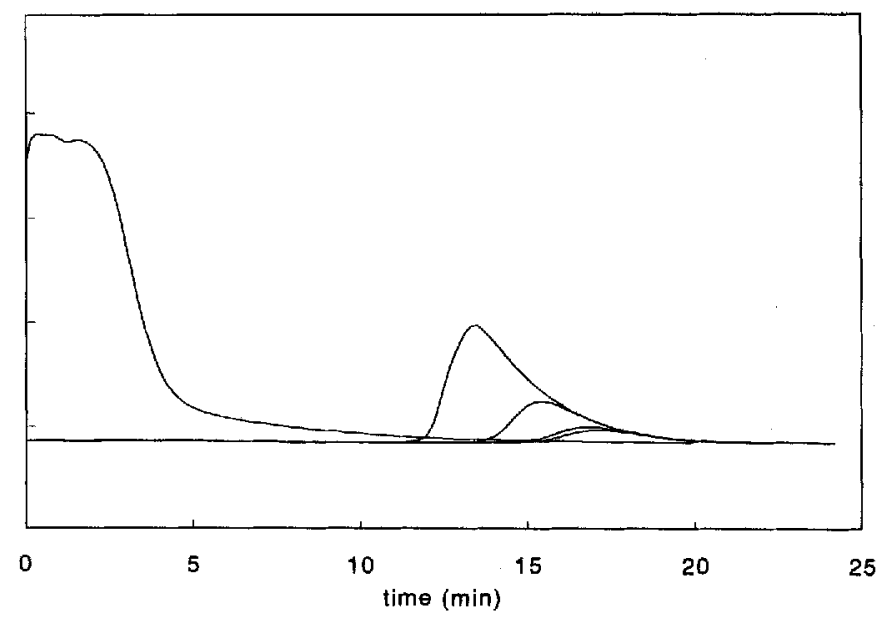

Figure 4. SFE elution profile of cyclohexanone from ODS and SFC chromatograms at different sample sizes. Experimental conditions: 300 bar and $40^{\circ} \mathrm{C} ; \mathrm{SFE}$ was performed by dynamic extraction after a 5 minutes static period.

time around $t_{0}$ (the time needed to elute the void volume of the extraction cell). From a comparison of the SFE elution profile with the SFC chromatogram, it can be seen that extraction is already complete before the time required to fully elute cyclohexanone in the SFC experiment.

In order to investigate whether the SFE extraction yields are affected by the concentrations of the solutes in the sample, two model systems were studied in detail. The first system involved the extraction of non-polar solutes from ODS. The other system combined a polar solute, hexadecanol with sand as the matrix. The components were extracted at a gaseous carbon dioxide flow rate of approximately $60 \mathrm{ml} / \mathrm{min}$ for 3 minutes after a 5 minute static period. The results are listed in Table 1 and Table 2, respectively. As can be seen from Table 1, no effect of the solute concentration on the SFE behavior is observed for the extraction of dodecane or eicosane from ODS. Analogously, the capacity factors of dodecane and eicosane on ODS in SFC are independent of the concentration of the components. Another interesting conclusion that can be drawn from the results presented in Table 1 is that the experimental extraction yields are in good agreement with the data calculated according to eq. (11).

Table 1. Comparison of experimental extraction yields and calculated data for octadecane and eicosane on ODS at different concentrations. (Extraction conditions: 5 min static extraction followed by 3 min dynamic extraction at $50^{\circ} \mathrm{C}$ and 300 bar.)

\begin{tabular}{|c|c|c|c|c|}
\hline $\begin{array}{l}\text { spiked } \\
\text { amount } \\
(\mu g)\end{array}$ & $\begin{array}{l}\text { exp. } \\
\text { yield } \\
(\%)\end{array}$ & $\begin{array}{l}\mathrm{C} 18^{\mathrm{a})} \\
\text { calc. } \\
\text { yield } \\
(\%)\end{array}$ & $\begin{array}{l}\text { exp. } \\
\text { yield } \\
(\%)\end{array}$ & $\begin{array}{l}\mathrm{C} 20^{\mathrm{b})} \\
\text { calc. } \\
\text { yield } \\
(\%)\end{array}$ \\
\hline 200 & 20.2 & 19.8 & 16.6 & 16.5 \\
\hline 100 & 19.7 & 21.0 & 16.4 & 17.5 \\
\hline 50 & 20.8 & 21.0 & 16.9 & 17.0 \\
\hline 20 & 19.9 & 20.9 & 15.7 & 16.7 \\
\hline 10 & 19.1 & 21.0 & 15.9 & 15.8 \\
\hline
\end{tabular}

a) with eicosane as the internal standard;

b) with octadecane as the internal standard.
Table 2. Comparison of extraction yields of hexadecanol from sand at different concentrations. (Extraction conditions: $5 \mathrm{~min}$ static extraction followed by a 3 min dynamic extraction at $50^{\circ} \mathrm{C}$ and 200 bar.)

\begin{tabular}{ll}
\hline spiked amount $(\mu \mathrm{g})$ & extraction yield $(\%)^{\mathrm{a})}$ \\
\hline 100 & 49.2 \\
50 & 45.8 \\
20 & 40.2 \\
10 & 37.0 \\
\hline
\end{tabular}

a) with eicosane as the internal standard.

For the extraction of hexadecanol from sand, a different situation occurs. Here, the solute retention in the SFC mode is a function of solute concentration. Hence, the equations derived in the theory section can not be applied for this solute/matrix combination. The extraction yields at different concentration levels are listed in Table 2. From this table, it can be seen that higher extraction yields were obtained at higher hexadecanol concentrations. This observation is in agreement with expectations because the capacity factors of hexadecanol on sand were found to decrease at increasing concentration levels due to the non-linearity of the adsorption isotherm. The dependence of extraction yield on analyte concentration in SFE further complicates SFE method development. Experimental conditions that give good recoveries for samples containing high solute concentrations might yield poor extraction recoveries for low-concentration samples.
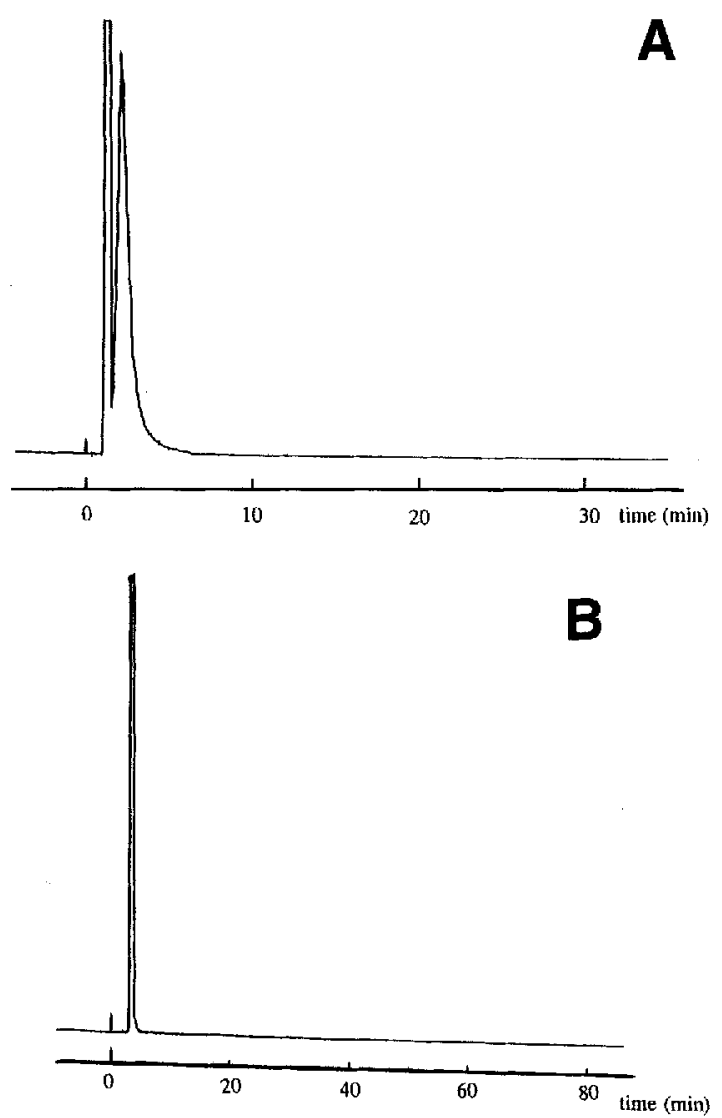

Figure 5. SFC chromatograms of hexadecanol on sand and on ODS. Chromatographic conditions: 200 bar and $50^{\circ} \mathrm{C}$. $5 \mathrm{~A}$ : on sand; $5 \mathrm{~B}$ : on ODS. 
It is interesting to compare the SFE results obtained in the extraction of hexadecanol from sand with those in the extraction of this component from ODS. Hexadecanol can easily be eluted from sand even at fairly mild conditions (Figure 5a). On the contrary, it is strongly retained on ODS. On this material no peak was observed under the same experimental conditions (Figure 5b). In SFE after 3 minutes' dynamic extraction at $50^{\circ} \mathrm{C}$ and 200 bar, nearly $50 \%$ of hexadecanol was extracted from sand, while only a negligible percentage (1.5\%) was extracted from ODS under identical experimental conditions (Table 3). This difference in extraction yields proves that variations in the composition of the sample matrix can have a large impact on the extraction rate in SFE. A practical consequence of this is that the extraction conditions required are strongly matrix dependent. This again supports the presumption that the distribution coefficient is one of the most important parameters in SFE. Moreover, it emphasizes that SFC retention data can be useful in predicting SFE recoveries as well as in optimizing SFE extraction conditions.

Table 3. Comparison of extraction yields of hexadecanol from sand and ODS ${ }^{\text {a) }}$ (Extraction conditions: 5 min static extraction followed by 3 min dynamic extraction at $50^{\circ} \mathrm{C}$ and 200 bar.)

\begin{tabular}{ll}
\hline sand & ODS \\
\hline $49.2 \%$ & $1.5 \%$ \\
\hline
\end{tabular}

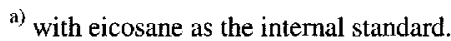

For homogeneous systems SFE conditions can be predicted directly from SFC experiments. For inhomogeneous systems that exhibit strong matrix effects or for systems where the extraction rate is determined by diffusion in the sample, a direct transfer of SFC retention data to SFE extraction yields is not possible. However, SFC retention data can still be useful. If a solute requires extreme elution conditions in SFC, extraction in SFE will certainly be difficult.

\section{Conclusions}

Supercritical-fluid chromatography offers an attractive method for examining the effects of experimental parameters on the extraction behavior in supercritical fluid extraction. A model is derived that enables the prediction of SFE extraction yields in bóth static and dynamic extraction from SFC retention data measured using the matrix that is to be extracted as the stationary phase. For samples in which the extraction kinetics are controlled by transfer of the components from the surface of the matrix into the extraction fluid and by subsequent elution out of the extraction cell, experimental extraction yields and predicted data are in good agreement. Extraction of components from solid sorbents is controlled by many of the same factors that control retention in SFC. Variations in sample matrix composition were found to require a substantial adjustment of the extraction parameters. For inhomogeneous samples, solute concentration can have a considerable effect on SFE kinetics.

\section{References}

[1] T.L. Chester, J.D. Pinkston, and D.E. Raynie, Anal. Chem. 64 (1992) 153.

[2] M.L. Lee and K.E. Markides (eds), Analytical Supercritical Chromatography and Extraction, Chromatography Conference, Provo, UT, 1990.

[3] D.R. Gere, C.R. Knipe, P. Castelli, J. Hedrich, L.G. Randall, H. Schulenberg-Schell, R. Schuster, L. Doherty, J. Orolin, and H.B. Lee, J. Chromtogr. Sci. 31 (1993) 246.

[4] X. Lou, H.-G. Janssen, and C.A. Cramers, J. High Resol. Chromatogr. 16 (1993) 425.

[5] R.J. Houben, H.-G.M. Janssen, P.A. Leclereq, J.A. Rijks, and C.A. Cramers, J. High Resol. Chromatogr. 13 (1990) 669

[6] K.D. Bartle, A.A. Clifford, and G.F. Shilstone, J. Supercrit. Fluids (1989) 30.

[7] J.W. King, J. Chromatogr. Sci. 27 (1989) 355

[8] M.E.P. McNally and J.R. Wheeler, J. Chromatogr. 447 (1988) 53.

[9] J.R. Wheeler and M.E. McNally, J. Chromatogr. Sci. 27 (1989) 534.

「10] K.G. Furton and Q. Lin, J. Chromatogr. Sci. 31 (1993) 201.

[11] G.F. Shilstone, M.W. Raynor, K.D. Bartle, A.A. Clifford, I.L. David, and S.A. Jafar, Polycycl. Aromat. Compd. 1 (1990) 99.

[12] J.C. Giddings, M.N. Myers, L. McLaren, and R. A. Keller, Science 162 (1968) 67.

[13] J.W. King and J.P. Friedrich, J. Chromatogr. 517 (1990) 449.

[14] E. Stahl, W. Schilz, E. Schutz, and E. Willing, Angew. Chem. Int. Ed. Engl. 17 (1978) 731.

[15] J. Rein, C.M. Cork, and K.G. Furton, J. Chromatogr. 545 (1991) 149.

[16] J. Pawliszyn, J. Chromatogr. Sci. 31 (1993) 31.

[17] P.J. Schoenmakers, L.G.M. Uunk, and P.K. de Bokx, J. Chromatogr. 459 (1988) 201.

[18] J.G.M. Janssen, P.J. Schoenmakers, and C.A. Cramers, J. High Resol. Chromatogr. 12 (1989) 645

[19] D.J. Miller, S.B. Hawthorne, and M.E.P. MeNally, Anal. Chem. 38 (1993) 1038.

[20] H.-G. Janssen, P.J. Schoenmakers, and C.A. Cramers, J. Chromatogr. 552 (1991) 527. Ms received: September 28,1995 accepted: July 18, 1995 